\title{
Treatment patterns associated with stroke prevention in patients with atrial fibrillation in three major cities in the People's Republic of China
}

\author{
This article was published in the following Dove Press journal: \\ International Journal of General Medicine \\ 18 December 2013 \\ Number of times this article has been viewed
}

\author{
Bao Liu' \\ Larry Z Liu ${ }^{2,3}$ \\ Jianwei Xuan² \\ Man Luo 4 \\ Yansheng $\mathrm{Li}^{5}$ \\ Chaohui Duan 6 \\ Hongqin Cheng ${ }^{7}$ \\ Xiaohui Yang ${ }^{8}$ \\ 'School of Public Health, Fudan \\ University, Shanghai, People's \\ Republic of China; 'Pfizer Inc, \\ New York, NY, USA; ${ }^{3}$ Weill Medical \\ College of Cornell University, New \\ York, NY, USA; ${ }^{4}$ Zhongshan Hospital, \\ Fudan University, Shanghai, People's \\ Republic of China; ${ }^{5}$ Renji Hospital, \\ Shanghai Jiaotong University, \\ Shanghai, People's Republic of China; \\ ${ }^{6}$ The Sun Yat-Sen Memorial Hospital, \\ Sun Yat-Sen University, Guangzhou, \\ People's Republic of China; ${ }^{7}$ Xuanwu \\ Hospital, Beijing, People's Republic \\ of China; ${ }^{8}$ Beijing Anzhen Hospital, \\ Capital University of Medical Science, \\ Beijing, People's Republic of China
}

Correspondence: Bao Liu School of Public Health, Fudan University, I 38 Yi Xue Yuan Road, Shanghai 200032, People's Republic of China

Tel +862I 54237764

Fax +86216403 893I

Email liub@fudan.edu.cn
Background: Atrial fibrillation (AF) is associated with an increased risk of stroke. This study assessed treatment patterns associated with stroke prevention among patients with AF in three major cities of the People's Republic of China.

Methods: A random sample of 2,862 medical charts for patients with AF at six tertiary hospitals located in Beijing, Shanghai, and Guangzhou between 2003 and 2008 were reviewed. Patient demographics, clinical characteristics, and treatment patterns were extracted from medical charts. Antithrombotic regimens included antiplatelets, anticoagulants, and a combination of both Descriptive analyses were performed to summarize basic antithrombotic patterns. A logistic regression model examined demographic and clinical factors associated with antithrombotic treatment patterns.

Results: Of the patient sample, 55\% were male, the average age was 72 years ( $49 \% \geq 75$ years), $15 \%$ had valvular AF, $78 \%$ had nonvalvular AF, and the remainder had unspecified AF. CHADS scores $\geq 2$ were reported for $53 \%$ of patients. Antithrombotic treatment was not received by $17 \%$ of patients during hospitalization, and $66 \%$ did not receive warfarin. Among patients with valvular or nonvalvular AF, 33\%, 30\%, and 20\% received antiplatelet, anticoagulation, and antiplatelet plus anticoagulation treatments, respectively. For patients with $\mathrm{CHADS}_{2}$ scores of $0,1,2,3$, and $\geq 4,52 \%, 42 \%, 28 \%, 21 \%$, and $21 \%$, respectively, were treated with warfarin. Predictors of no antithrombotic treatment included age and hospital location.

Conclusion: Anticoagulation therapy was underused in Chinese patients with AF. Antithrombotic treatment was not associated with stroke risk. Further studies need to examine the clinical consequences of various antithrombotic treatment patterns in Chinese patients with AF.

Keywords: atrial fibrillation, stroke prevention, antithrombotic treatment, China

\section{Introduction}

Atrial fibrillation (AF) is the most common sustained cardiac arrhythmia. This irregular heart rhythm occurs when circuits of disorganized electrical activity in the atria replace the organized electrical activity normally generated by the heart. Age, hypertension, congestive heart failure, valvular disease, and diabetes are known risk factors for the development of AF. ${ }^{1-4}$ More than 5 million people in the US and over 6 million in Europe are affected. ${ }^{5,6}$ A large epidemiologic survey conducted in 2002 reported a $0.77 \%$ prevalence of AF in the People's Republic of China, which is close to the $1 \%-2 \%$ prevalence rates reported for the general population in developed regions. ${ }^{6,7}$ 
Nearly $18 \%$ of all cerebrovascular events in Europe are associated with $\mathrm{AF} .{ }^{8} \mathrm{AF}$ increases the risk of ischemic stroke five-fold when compared with normal sinus rhythm. ${ }^{9,10}$ About one in five strokes is attributed to AF, and the ratio is even higher in the elderly. ${ }^{11} \mathrm{AF}$-related stroke has become a prominent source of morbidity and mortality and is associated with a high cost of care, so stroke prevention is considered an independent cornerstone strategy for patients with AF. Anticoagulation or antiplatelet therapy has been well documented in both guidelines for stroke prevention and guidelines for the management of AF. ${ }^{6,12}$

The People's Republic of China has been following the development of international AF treatment guidelines from the American College of Cardiology/American Heart Association/European Society of Cardiology, ${ }^{13,14}$ European Society of Cardiology, ${ }^{6}$ American College of Chest Physicians, ${ }^{15}$ and American Heart Association/American Stroke Association. ${ }^{16}$

Central to these guidelines is stratification of stroke risk to balance the risks of bleeding and of thromboembolism. Recently, these guidelines have introduced new antithrombotic alternatives to warfarin that may lower the risk threshold for initiating antithrombotic therapy in patients with AF. In the People's Republic of China, informal guidelines were published 10 years ago, with an expert consensus issued in 2006. ${ }^{17}$ AF studies in the People's Republic of China have indicated a direct correlation between the burden of AFrelated stroke and underuse of anticoagulation therapy. ${ }^{7,18}$ Taking into consideration the findings of recent studies and of the recent AF treatment guideline updates, this study sought to identify and assess treatment patterns associated with stroke prevention in three major cities of the People's Republic of China in an effort to inform future preventive strategies for AF-related stroke in that country.

\section{Materials and methods}

Medical charts recorded for patients hospitalized with a primary diagnosis of AF (International Classification of Diseases, Ninth Revision, ${ }^{19}$ Clinical Modification, diagnosis code 427.31) at six tertiary hospitals located in three major cities of the People's Republic of China (Beijing, Shanghai, and Guangzhou) between 2003 and 2008 were used for this study.

All six hospitals had a specific center or cardiology department for AF treatment and were selected based on their willingness to participate in the study. In each hospital, the charts for 480 patients (400 with nonvalvular and 80 with valvular AF) were randomly chosen. A proportional sampling method, based on the annual number of patients with AF at each hospital from 2003 to 2008, was employed so that the 480 patients would adequately represent the distribution of patients with AF by year. Trained physicians and medical students reviewed the medical charts and extracted data using the structured data extraction form, including patient demographics, clinical characteristics, and antithrombotic treatment patterns. Specific variables included age, sex, AF diagnosis, and $\mathrm{CHADS}_{2}$ score $^{20}$ (determined by assigning and adding points for the following conditions: one point each for congestive heart failure, hypertension, age $\geq 75$ years, and diabetes, and two points for prior stroke or transient ischemic attack). ${ }^{20}$ The $\mathrm{CHADS}_{2}$ score is a clinical predictor of stroke risk in patients with $\mathrm{AF}$ and a useful instrument for determining whether or not to initiate anticoagulation therapy. ${ }^{21}$ In addition to descriptive statistics, a logistic regression model was used to investigate the effect of clinical and demographic factors on antithrombotic treatment patterns.

Independent predictors in the logistic regression model included age, sex, type of $\mathrm{AF}, \mathrm{CHADS}_{2}$ score, and city dummies. A two-sided $P$-value less than 0.05 was considered to be statistically significant. All analyses were performed using Stata version 12 statistical software (Stata Corporation, College Station, TX, USA).

\section{Results \\ Patient characteristics}

Of the 2,862 patient charts reviewed between January 2003 and December 2008, 34\% were from Beijing, 33\% from Shanghai, and 33\% from Guangzhou. Fifty-five percent of the total charts reviewed were for male patients. The average patient age was 72 years (standard deviation 13.3), and nearly one half of all patients (49\%) were 75 years or older. Among all patients, $15 \%$ had valvular AF, 78\% had nonvalvular $\mathrm{AF}$, and $8 \%$ had an unidentified type of $\mathrm{AF}$. The mean ages of patients with valvular and nonvalvular AF were 67 and 72 years, respectively. A greater proportion of males had nonvalvular $(60 \%)$ than valvular $(36 \%) \mathrm{AF}$. The $\mathrm{CHADS}_{2}$ score was calculated for each of the study patients. Among patients with nonvalvular AF, $53 \%$ had a $\mathrm{CHADS}_{2}$ score $\geq 2$. Although not designed for use in valvular AF, when $\mathrm{CHADS}_{2}$ scores were assessed in patients with valvular AF, $45 \%$ had a CHADS $_{2}$ score $\geq 2$. About $36 \%$ of the patients in the study were diagnosed with a first episode of AF. Paroxysmal, permanent, and persistent $\mathrm{AF}$ accounted for $47 \%, 33 \%$, and $7 \%$ of the patients studied, respectively. In those patients for whom the AF was not a first episode, the median duration 
of AF was 4.2 years. Table 1 summarizes the characteristics of the study population.

\section{Antithrombotic treatment patterns for stroke prevention}

Table 2 displays the distribution of antithrombotic treatment patterns by number of therapy types. Approximately $17 \%$ of patients did not receive any antiplatelet or anticoagulation treatment during their hospital stay. For patients with valvular or nonvalvular $\mathrm{AF}, 42 \%$ received one treatment (19\% received aspirin, 13\% warfarin, 5\% clopidogrel, and $4 \%$ low molecular weight heparin [LMWH]); 30\% received a two-drug regimen (12\% received warfarin plus LMWH, 7\% aspirin plus clopidogrel, 3\% warfarin plus aspirin, 3\% aspirin plus LMWH, and 5\% other combinations); $9 \%$ received a three-drug regimen (4\% aspirin plus clopidogrel and LMWH, $2 \%$ warfarin plus aspirin and LMWH, 1\% warfarin plus aspirin and clopidogrel, 1\% warfarin plus clopidogrel and LMWH, and $1 \%$ other combinations); and $2 \%$ received a four-drug or five-drug regimen. The antithrombotic treatment patterns differed significantly $(P=0.000$, Fisher's exact test) between patients with valvular and nonvalvular AF. The proportion of patients receiving a one-drug antithrombotic regimen was much higher among patients with valvular than nonvalvular AF (57\% versus 39\%, respectively). Further, antithrombotic treatment patterns for the three cities showed a higher proportion of patients with AF not receiving any antithrombotic therapy in Guangzhou than in Beijing or Shanghai. A lower proportion of patients with AF received a one-drug antithrombotic regimen in Beijing than in Shanghai, whereas a higher proportion received at least a two-drug regimen in Beijing than in Guangzhou. In general, significant differences $(P=0.000$, Pearson's chi-square test when putting together patterns with two or more types of drugs) in antithrombotic treatment patterns existed among the three cities in the People's Republic of China.

Table 3 and Figure 1 further depict the distribution of antithrombotic treatment patterns for patients with valvular and nonvalvular AF. Antiplatelet, anticoagulation, and

Table I Patient characteristics

\begin{tabular}{|c|c|c|c|c|}
\hline Characteristic, \% & Total & Beijing & Shanghai & Guangzhou \\
\hline Male & 55.4 & 56.7 & 57.5 & 51.9 \\
\hline Age $\geq 75$ years & 49.1 & 36.8 & 48.0 & 63.0 \\
\hline Nonvalvular AF & 77.6 & 82.1 & 71.4 & 79.2 \\
\hline $\mathrm{CHADS}_{2}$ score $^{20} \geq 2$ & 53.0 & 41.5 & 53.0 & 64.7 \\
\hline First episode of AF & 36.2 & 30.5 & 23.8 & 54.8 \\
\hline
\end{tabular}

Abbreviation: $\mathrm{AF}$, atrial fibrillation. antiplatelet plus anticoagulation therapies were used in 33\%, $30 \%$, and $20 \%$ of patients, respectively, whereas $17 \%$ did not receive any antithrombotic treatment. The combined percentage of patients with valvular AF treated with anticoagulation alone or antiplatelet plus anticoagulation therapy was higher than that of patients with nonvalvular AF (66\% versus $48 \%$ ). The percentages of all patients receiving no antithrombotic regimen, aspirin only, warfarin only or combinations, and other were $17 \%, 19 \%, 36 \%$, and $28 \%$, respectively. The four antithrombotic treatment patterns differed significantly between patients with valvular $\mathrm{AF}$ and those with nonvalvular $\operatorname{AF}(P=0.001$, Pearson's chi-square test). A higher percentage of patients with valvular AF were receiving warfarin only or combinations ( $59 \%$ versus $31 \%$ for patients with nonvalvular $\mathrm{AF})$, whereas a lower percentage were receiving aspirin only (13\% versus $21 \%$, respectively).

\section{Factors associated with antithrombotic treatment}

The $\mathrm{CHADS}_{2}$ score is a simple and well validated prediction tool. ${ }^{20}$ Although recently developed, ${ }^{22,23}$ the $\mathrm{CHADS}_{2}$ score is commonly used to help elucidate antithrombotic treatment patterns in clinical settings. In this study, $86 \%, 83 \%, 81 \%$, $78 \%$, and $85 \%$ of patients with $\mathrm{AF}$ and $\mathrm{CHADS}_{2}$ scores of $0,1,2,3$, and 4 or above, respectively, were treated with any antithrombotic regimen (Table 4). No significant difference in the proportion of patients using any antithrombotic treatment was discerned among the $\mathrm{CHADS}_{2}$ score categories of 0,1 , and $\geq 2$ ( $P=0.067$, Fisher's exact test). However, when patients with an unidentified AF type were excluded, the differences in antithrombotic treatment were significant ( $P=0.046$, Fisher's exact test). Further, patients with higher $\mathrm{CHADS}_{2}$ scores $(\geq 2)$ were less likely to receive warfarin or combinations, whereas patients with $\mathrm{CHADS}_{2}$ scores of 0 or 1 were more likely to receive warfarin or combinations (Table 4).

Table 5 shows the association between stroke risk factors and antithrombotic regimen used under the framework of multivariate regression analysis. The logistic regression model incorporated a dichotomous dependent variable of antithrombotic use and dummy variables for $\mathrm{CHADS}_{2}$ score $(0,1$, and $\geq 2)$, type of AF (valvular or nonvalvular), sex, age, and city as predictors.

The choice of antithrombotic regimen was not associated with $\mathrm{CHADS}_{2}$ score. Patients $\geq 75$ years of age were significantly less likely than younger patients to receive an antithrombotic regimen. Antithrombotic practices in hospitals in Guangzhou and Shanghai differed significantly, although 
Table 2 Distribution of antithrombotic treatment patterns

\begin{tabular}{|c|c|c|c|c|c|c|}
\hline \multirow[b]{2}{*}{$\begin{array}{l}\text { Drug types in } \\
\text { regimen }(n)\end{array}$} & \multirow[b]{2}{*}{$\begin{array}{l}\text { Total } \\
(n=2,637)^{a}\end{array}$} & \multicolumn{2}{|l|}{ AF type } & \multicolumn{3}{|l|}{ City } \\
\hline & & $\begin{array}{l}\text { Valvular } \\
(n=4 \mid 7)^{a}\end{array}$ & $\begin{array}{l}\text { Nonvalvular } \\
(n=2,220)\end{array}$ & $\begin{array}{l}\text { Beijing } \\
(n=960)\end{array}$ & $\begin{array}{l}\text { Shanghai } \\
(n=782)\end{array}$ & $\begin{array}{l}\text { Guangzhou } \\
(n=895)\end{array}$ \\
\hline $0^{\mathrm{b}}$ & $444(16.8)$ & $60(14.4)$ & $384(17.3)$ & $152(15.8)$ & $96(12.3)$ & $196(21.9)$ \\
\hline I & $\mathrm{I}, 108(42)^{\mathrm{c}}$ & $236(56.6)$ & $872(39.3)$ & $302(3 \mid .5)$ & $375(48)$ & $43 I(48.2)$ \\
\hline 2 & $798(30.3)^{d}$ & $88(2 \mathrm{I} . \mathrm{I})$ & $710(32)$ & $360(37.5)$ & $224(28.6)$ & $214(23.9)$ \\
\hline 3 & $239(9.1)$ & $25(6)$ & $214(9.6)$ & II3 (II.8) & $79(10.1)$ & $47(5.3)$ \\
\hline 4 & $46(1.7)$ & $8(1.9)$ & $38(1.7)$ & $3 \mid(3.2)$ & $8(1)$ & $7(0.8)$ \\
\hline 5 & $2(0.1)$ & 0 & $2(0.1)$ & $2(0.2)$ & 0 & 0 \\
\hline
\end{tabular}

Notes: Figures in parentheses are column percentages; ${ }^{a}$ five records without clear specification of treatment pattern were dropped in tabulation; ${ }^{b}$ no antithrombotic treatment; ' ${ }^{\text {within }} 42 \%$ : $19 \%$ of patients received aspirin, $13 \%$ warfarin, $5 \%$ clopidogrel, and $4 \% \mathrm{LMWH}$; ${ }^{\mathrm{d}}$ within $30 \%$ : I $2 \%$ of patients received warfarin plus $\mathrm{LMWH}$, $7 \%$ aspirin plus clopidogrel, $3 \%$ warfarin plus aspirin, $3 \%$ aspirin plus $\mathrm{LMWH}$, and $5 \%$ other combinations.

Abbreviations: AF, atrial fibrillation; LMWH, low molecular weight heparin.

in opposite ways, from those in Beijing. Antithrombotic regimens seemed to be given more consideration in Shanghai than in Beijing or Guangzhou.

\section{Discussion}

Cerebral vascular disease has become the leading cause of death in China, accounting for $22.5 \%$ of all deaths. Stroke, the cost of which is substantial in all countries, ${ }^{24-27}$ contributes to a major portion of cerebral vascular deaths. ${ }^{28}$ Given that approximately $20 \%$ of all strokes are attributed to $\mathrm{AF}$, a comprehensive program of stroke prevention must pay close attention to antithrombotic treatments. ${ }^{8,11}$

Vitamin $\mathrm{K}$ antagonists (eg, warfarin) and aspirin are commonly prescribed to prevent stroke in patients with AF. In patients with nonvalvular AF, the risk of stroke is reduced by approximately $20 \%$ with aspirin and by approximately $60 \%$ with adjustable-dose warfarin. ${ }^{29}$ However, the risk of bleeding and the difficulty of monitoring and maintaining international normalized ratio (INR) values in the therapeutic range with vitamin $\mathrm{K}$ antagonists limit their usefulness. The effects of warfarin on the clotting cascade vary from patient to patient, in part because of individual genetics but also because of the interaction of warfarin with foods,

Table 3 Antiplatelet and anticoagulation treatment patterns

\begin{tabular}{|c|c|c|c|}
\hline \multirow[b]{2}{*}{ Treatment pattern } & \multirow[b]{2}{*}{$\begin{array}{l}\text { Total } \\
(n=2,637)\end{array}$} & \multicolumn{2}{|l|}{ AF type } \\
\hline & & $\begin{array}{l}\text { Valvular } \\
(n=417)\end{array}$ & $\begin{array}{l}\text { Nonvalvular } \\
(n=2,220)\end{array}$ \\
\hline $\begin{array}{l}\text { No antithrombotic } \\
\text { treatment }\end{array}$ & $444(16.8)$ & $60(14.4)$ & $384(17.3)$ \\
\hline Antiplatelet & $860(32.6)$ & $80(19.2)$ & $780(35.1)$ \\
\hline Anticoagulation & $801(30.4)$ & $211(50.6)$ & $590(26.6)$ \\
\hline $\begin{array}{l}\text { Antiplatelet plus } \\
\text { anticoagulation }\end{array}$ & $532(20.2)$ & $66(15.8)$ & $466(21.0)$ \\
\hline
\end{tabular}

Note: Figures in parentheses are percentages.

Abbreviation: AF, atrial fibrillation. alcohol, and other medications. Concerns over bleeding can lead to undertreatment, causing a measurable increased risk of thrombosis.

Underuse of anticoagulant therapy in patients with AF has been well documented around the world. Studies have shown that nearly one half of patients with AF and additional risk factors for stroke and without contraindications did not receive vitamin $\mathrm{K}$ antagonists. ${ }^{30,31}$ A study in the People's Republic of China showed that less than 3\% of patients with $\mathrm{AF}$ received warfarin, and even fewer patients taking warfarin had adequate monitoring of INR. Only $20.1 \%$ of patients with $\mathrm{AF}$ in the People's Republic of China take aspirin, which is much lower than rates of aspirin use in the US and Europe. ${ }^{32-34}$

The current study provides evidence of relatively stable aspirin use (19\%) and improved warfarin use (36\%) among patients with AF in three major cities of the People's Republic of China. However, the fact that $17 \%$ of patients with both valvular and nonvalvular AF did not receive any antithrombotic regimen underscores the need to further increase use of antithrombotic treatment in these patients. Identified predictors of no treatment included age and hospital location.

The $\mathrm{CHADS}_{2}$ score is an effective predictor of stroke risk, with higher scores indicating increased risk. However, the current study showed that an antithrombotic regimen was not prescribed according to stroke risk based on the $\mathrm{CHADS}_{2}$ score. Further modeling using a multinomial logit model (results not presented) revealed no significant association between $\mathrm{CHADS}_{2}$ score and preference for no antithrombotic treatment, a one-drug antithrombotic regimen, or a multidrug regimen. Further, a CHADS 2 score of 2 or above did not associate well with warfarin use. The existing reluctance to use warfarin in clinical practice suggests that the entry of novel oral anticoagulants could replace warfarin. 


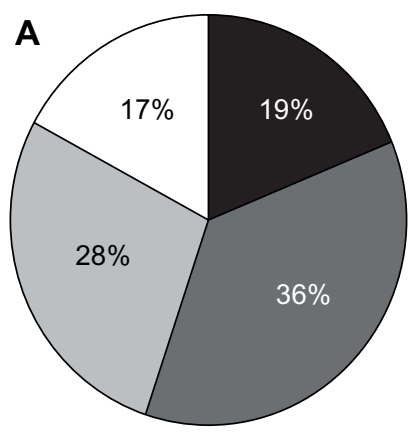

$n=2,637$

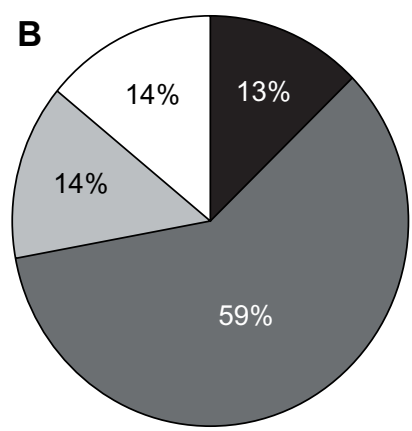

$\mathrm{n}=417$

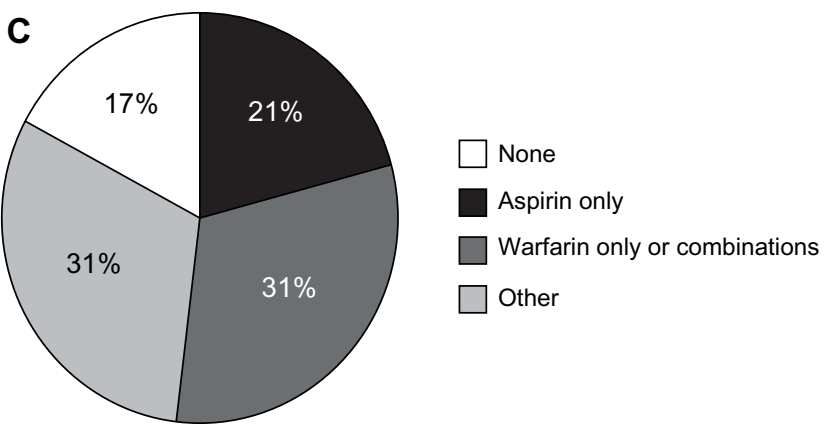

$n=2,220$

Figure I Overall treatment patterns for patients with (A) valvular and nonvalvular AF, (B) valvular AF, and (C) nonvalvular AF. Abbreviation: AF, atrial fibrillation.

It is well acknowledged that stroke risk increases with age. An expanded version of the $\mathrm{CHADS}_{2}$ score, ie, the $\mathrm{CHA}_{2} \mathrm{DS}_{2}-$ VASc score, includes additional stroke risk factors and gives "age 75 years or above" extra weight (with two points). ${ }^{25,35}$ However, the current study's logistic regression model did not show age $\geq 75$ years to be a significant predictor of antithrombotic use. The study showed that, in the People's Republic of China, the elderly (aged $\geq 75$ years) were treated more often with antiplatelet therapy than were younger patients $(42 \%$ versus $27 \%$, results not presented), whereas the elderly were treated less often with anticoagulation (or antiplatelet plus anticoagulation) therapy than were younger patients $(35 \%$ versus $59 \%$, results not presented). The result of the logistic regression analysis, ie, that patients 75 years of age or older are less likely to receive antithrombotics, might partly reflect the fact that the $\mathrm{CHADS}_{2}$ score did not accurately predict antithrombotic treatment patterns in the People's Republic of China (age $\geq 75$ years is a component of $\mathrm{CHADS}_{2}$ ). That the antithrombotic treatment pattern in China does not follow current clinical practice guidelines warrants further study to determine the reasons why this is so.

The logistic regression model also did not show any significant association between sex and choice of

Table 4 Patients treated with an antithrombotic regimen, by $\mathrm{CHADS}_{2}$ score

\begin{tabular}{|c|c|c|c|}
\hline $\begin{array}{l}\text { CHADS }_{2} \\
\text { score }^{20}\end{array}$ & $\begin{array}{l}\text { Patients } \\
\text { receiving any } \\
\text { antithrombotic } \\
\text { regimen, } \mathrm{n}(\%)\end{array}$ & $\begin{array}{l}\text { Patients } \\
\text { receiving } \\
\text { warfarin or } \\
\text { combinations, \% }\end{array}$ & $\begin{array}{l}\text { Patients } \\
\text { receiving } \\
\text { aspirin } \\
\text { only, \% }\end{array}$ \\
\hline $0(n=494)$ & $423(85.6)$ & 51.8 & 15.8 \\
\hline I $(n=852)$ & 703 (82.5) & 41.9 & 17.1 \\
\hline $2(n=648)$ & $523(80.7)$ & 28.4 & 26.1 \\
\hline $3(n=444)$ & 347 (78.2) & 21.4 & 22.7 \\
\hline $4+(n=424)$ & 359 (84.7) & 21.2 & 23.8 \\
\hline All $(n=2,862)$ & $2,355(82.2)$ & 34.3 & 20.8 \\
\hline
\end{tabular}

antithrombotic regimen. Although all of the hospitals studied, irrespective of location, preferred use of warfarin in antithrombotic practice, hospitals in Guangzhou were significantly less likely to prescribe an antithrombotic regimen for patients with AF than were hospitals in Shanghai and Beijing. Physicians in the tertiary hospitals selected in Shanghai and Beijing adhered more to international AF treatment guidelines than did those in the selected Guangzhou hospitals.

Several limitations may hinder the generalization of this study's results. First, treatment patterns for stroke prevention in patients with $\mathrm{AF}$ from the six selected tertiary hospitals may not be indicative of such treatment patterns for all patients with AF hospitalized in the People's Republic of China. Second, this study included hospitalized patients only, and third, retrospective chart reviews such as this

Table 5 Multivariate regression analysis of the association between stroke risk factors and antithrombotic regimen used $(n=2,60 \mathrm{I})$

\begin{tabular}{|c|c|c|c|}
\hline Predictor & Patients, $\mathbf{n}$ & OR & $95 \% \mathrm{Cl}$ \\
\hline \multicolumn{4}{|l|}{$\mathrm{CHADS}_{2}$ score $^{19}$} \\
\hline 0 & 462 & & \\
\hline I & 786 & 0.85 & $0.61-1.19$ \\
\hline$\geq 2$ & $\mathrm{I}, 353$ & 1.05 & $0.74-1.48$ \\
\hline \multicolumn{4}{|l|}{ AF type } \\
\hline Valvular & 410 & & \\
\hline Nonvalvular & 2,191 & 0.82 & $0.60-1.11$ \\
\hline \multicolumn{4}{|l|}{ Age } \\
\hline$<75$ years & $\mathrm{I}, 664$ & & \\
\hline$\geq 75$ years & 937 & $0.55^{\mathrm{a}}$ & $0.43-0.70$ \\
\hline \multicolumn{4}{|l|}{ Sex } \\
\hline Male & $\mathrm{I}, 455$ & & \\
\hline Female & $\mathrm{I}, \mathrm{I} 46$ & 0.90 & $0.73-1.11$ \\
\hline \multicolumn{4}{|l|}{ City } \\
\hline Beijing & 947 & & \\
\hline Guangzhou & 882 & $0.75^{a}$ & $0.59-0.96$ \\
\hline Shanghai & 772 & $1.46^{\mathrm{b}}$ & $1.11-1.94$ \\
\hline
\end{tabular}


study are subject to potential coding errors and unmeasured biases. Finally, many patient and clinical characteristics such as prior history of bleeding or stroke, comorbid conditions, and concomitant medications were not included in this analysis.

In conclusion, antithrombotic treatment is substantially underused in patients with AF in China, particularly in older patients. Varied antithrombotic treatment patterns in the People's Republic of China could impact current and future antithrombotic treatment strategies. These include a strengthened approach to prescribing antithrombotic treatment by stroke risk, the prospective consideration of warfarin in antithrombotic regimens, and national coordination in adopting standardized antithrombotic practices that could help attenuate hospital costs for stroke in the People's Republic of China. ${ }^{36}$

\section{Acknowledgments}

Some of the data in this manuscript were previously presented at the American College of Cardiology's 60th Annual Scientific Session and i2 Summit, New Orleans, LA, April 2-5, 2011. Editorial support was provided by Dana Fox of Caudex Medical, and funded by Bristol-Myers Squibb Company and Pfizer, Inc.

\section{Disclosure}

Financial support for this study was provided entirely by Bristol-Myers Squibb Company and Pfizer Inc. The funding agreement helped ensure the authors' independence in designing the study, interpreting the data, and writing and publishing the report. BL is an employee of Fudan University, which received financial support from Bristol-Myers Squibb and Pfizer in connection with conducting this study and the development of this manuscript. LZL and JX are employees of Pfizer Inc. ML, YL, CD, HC, and XY received financial support from Bristol-Myers Squibb and Pfizer for collection of data for this study but were not paid for manuscript development. The authors report no other conflicts of interest.

\section{References}

1. Anné W, Willems R, Roskams T, et al. Matrix metalloproteinases and atrial remodeling in patients with mitral valve disease and atrial fibrillation. Cardiovasc Res. 2005;67(4):655-656.

2. Sanders P, Morton JB, Kistler PM, Vohra JK, Kalman JM, Sparks PB. Reversal of atrial mechanical dysfunction after cardioversion of atrial fibrillation: implications for the mechanisms of tachycardia-mediated atrial cardiomyopathy. Circulation. 2003;108(16):1976-1984.

3. Vaziri SM, Larson MG, Lauer MS, Benjamin EJ, Levy D. Influence of blood pressure on left atrial size. The Framingham Heart Study. Hypertension. 1995;25(6):1155-1160.
4. Benjamin EJ, Levy D, Vaziri SM, D’Agostino RB, Belanger AJ, Wolf PA. Independent risk factors for atrial fibrillation in a populationbased cohort. The Framingham Heart Study. JAMA. 1994;271(11): 840-844.

5. Miyasaka Y, Barnes ME, Gersh BJ, et al. Secular trends in incidence of atrial fibrillation in Olmsted County, Minnesota, 1980 to 2000, and implications on the projections for future prevalence. Circulation. 2006;114(2):119-125.

6. Camm AJ, Kirchhof P, Lip GY, et al; European Heart Rhythm Association; European Association for Cardio-Thoracic Surgery. Guidelines for the management of atrial fibrillation: the Task Force for the Management of Atrial Fibrillation of the European Society of Cardiology (ESC). Europace. 2010;12(10):1360-1420.

7. Zhou ZQ, Hu DY, Chen J, Zhang R, Li K, Zhao X. [An epidemiological survey of atrial fibrillation in China]. Chin J Intern Med. 2004;43: 491-494. Chinese.

8. Lamassa M, Di Carlo A, Pracucci G, et al. Characteristics, outcome, and care of stroke associated with atrial fibrillation in Europe: data from a multicenter multinational hospital-based registry (The European Community Stroke Project). Stroke. 2001;32(2):392-398.

9. Narayan SM, Cain ME, Smith JM. Atrial fibrillation. Lancet. 1997;350(9082):943-950.

10. Ryder KM, Benjamin EJ. Epidemiology and significance of atrial fibrillation. Am J Cardiol. 1999;84(9A):131R-138R.

11. Wolf PA, Abbott RD, Kannel WB. Atrial fibrillation as an independent risk factor for stroke: the Framingham Study. Stroke. 1991;22(8): 983-988.

12. Goldstein LB, Bushnell CD, Adams RJ, et al; American Heart Association Stroke Council; Council on Cardiovascular Nursing; Council on Epidemiology and Prevention; Council for High Blood Pressure Research; Council on Peripheral Vascular Disease, and Interdisciplinary Council on Quality of Care and Outcomes Research. Guidelines for the primary prevention of stroke: a guideline for healthcare professionals from the American Heart Association/ American Stroke Association. Stroke. 2011;42(2):517-584.

13. Fuster V, Rydén LE, Asinger RW, et al. ACC/AHA/ESC guidelines for the management of patients with atrial fibrillation: executive summary. A report of the American College of Cardiology/American Heart Association Task Force on Practice Guidelines and the European Society of Cardiology Committee for Practice Guidelines and Policy Conferences (Committee to Develop Guidelines for the Management of Patients With Atrial Fibrillation): developed in collaboration with the North American Society of Pacing and Electrophysiology. Circulation. 2001;104(17):2118-2150.

14. Fuster V, Rydén LE, Cannom DS, et al. ACC/AHA/ESC 2006 Guidelines for the Management of Patients with Atrial Fibrillation: a report of the American College of Cardiology/American Heart Association Task Force on Practice Guidelines and the European Society of Cardiology Committee for Practice Guidelines (Writing Committee to Revise the 2001 Guidelines for the Management of Patients With Atrial Fibrillation): developed in collaboration with the European Heart Rhythm Association and the Heart Rhythm Society. Circulation. 2006;114(7):e257-e354.

15. You JJ, Singer DE, Howard PA, et al; American College of Chest Physicians. Antithrombotic therapy for atrial fibrillation: Antithrombotic Therapy and Prevention of Thrombosis, 9th ed: American College of Chest Physicians Evidence-Based Clinical Practice Guidelines. Chest. 2012;141(Suppl 2):e531S-e575S

16. Furie KL, Goldstein LB, Albers GW, et al; American Heart Association Stroke Council; Council on Quality of Care and Outcomes Research; Council on Cardiovascular Nursing; Council on Clinical Cardiology; Council on Peripheral Vascular Disease. Oral antithrombotic agents for the prevention of stroke in nonvalvular atrial fibrillation: a science advisory for healthcare professionals from the American Heart Association/American Stroke Association. Stroke. 2012;43(12): $3442-3453$. 
17. Chen Xin, Zhang S, Hu D, et al; Working Group on Atrial Tachyarrhythmias of the Chinese Society of Pacing and Electrophysiology. Current knowledge and management recommendations of atrial fibrillation. Chin J Card Arrhythm. 2001;5:69-94. Chinese.

18. Hu DY, Sun YH, Zhou ZQ, et al. [Risk factors for stroke in Chinese with non valvular atrial fibrillation: a case-control study]. Chin J Intern Med. 2003;42:157-161. Chinese.

19. American Medical Association. International Classification of Diseases, 9th Revision. Clinical Modification 2005. Chicago, American Medical Association. 2005.

20. Gage BF, Waterman AD, Shannon W, Boechler M, Rich MW, Radford MJ Validation of clinical classification schemes for predicting stroke: results from the National Registry of Atrial Fibrillation. JAMA. 2001;285(22): 2864-2870.

21. Gage BF, van Walraven C, Pearce L, et al. Selecting patients with atrial fibrillation for anticoagulation: stroke risk stratification in patients taking aspirin. Circulation. 2004;110(16):2287-2292.

22. Karthikeyan G, Eikelboom JW. The $\mathrm{CHADS}_{2}$ score for stroke risk stratification in atrial fibrillation - friend or foe? Thromb Haemost 2010;104(1):45-48.

23. Lip GY, Nieuwlaat R, Pisters R, Lane DA, Crijns HJ. Refining clinical risk stratification for predicting stroke and thromboembolism in atrial fibrillation using a novel risk factor-based approach: the Euro Heart Survey on Atrial Fibrillation. Chest. 2010;137(2):263-272.

24. Taylor TN, Davis PH, Torner JC, Holmes J, Meyer JW, Jacobson MF. Lifetime cost of stroke in the United States. Stroke. 1996;27(9): 1459-1466.

25. Dewey HM, Thrift AG, Mihalopoulos C, et al. Lifetime cost of stroke subtypes in Australia: findings from the North East Melbourne Stroke Incidence Study (NEMESIS). Stroke. 2003;34(10):2502-2507.

26. Ghatnekar O, Persson U, Glader EL, Terént A. Cost of stroke in Sweden: an incidence estimate. Int J Technol Assess Health Care. 2004;20(3): 375-380.
27. Wang YL, Wu D, Liao X, Zhang W, Zhao X, Wang YJ. Burden of stroke in China. Int J Stroke. 2007;2(3):211-213.

28. Chen Z. Report of the 3rd National Retrospective Sampling Survey on the Cause of Death in China. Beijing, People's Republic of China: Peking Union Medical College Press; 2008.

29. Hart RG, Benavente O, McBride R, Pearce LA. Antithrombotic therapy to prevent stroke in patients with atrial fibrillation: a meta-analysis. Ann Intern Med. 1999;131(7):492-501.

30. Buckingham TA, Hatala R. Anticoagulants for atrial fibrillation: why is the treatment rate so low? Clin Cardiol. 2002;25(10):447-454.

31. Hollowell J. Is warfarin still underused in patients with atrial fibrillation? A literature review. Cerebrovasc Dis. 2004;17 Suppl 5:125.

32. Gage BF, Boechler M, Doggette AL, et al. Adverse outcomes and predictors of underuse of antithrombotic therapy in Medicare beneficiaries with chronic atrial fibrillation. Stroke. 2000;31(4):822-827.

33. Goldstein LB, Adams R, Alberts MJ, et al. Primary prevention of ischemic stroke: a guideline from the American Heart Association/ American Stroke Association Stroke Council: cosponsored by the Atherosclerotic Peripheral Vascular Disease Interdisciplinary Working Group; Cardiovascular Nursing Council; Clinical Cardiology Council; Nutrition, Physical Activity, and Metabolism Council; and the Quality of Care and Outcomes Research Interdisciplinary Working Group: the American Academy of Neurology affirms the value of this guideline. Stroke. 2006;37(6):1583-1633.

34. Nieuwlaat R, Capucci A, Camm AJ, et al; European Heart Survey Investigators. Atrial fibrillation management: a prospective survey in ESC member countries: the Euro Heart Survey on Atrial Fibrillation. Eur Heart J. 2005;26(22):2422-2434.

35. Lip GY, Halperin JL. Improving stroke risk stratification in atrial fibrillation. Am J Med. 2010;123(6):484-488.

36. Wei JW, Heeley EL, Jan S, et al; ChinaQUEST Investigators. Variations and determinants of hospital costs for acute stroke in China. PLoS One. 2010;5(9):pii:e13041.
International Journal of General Medicine

\section{Publish your work in this journal}

The International Journal of General Medicine is an international, peer-reviewed open-access journal that focuses on general and internal medicine, pathogenesis, epidemiology, diagnosis, monitoring and treatment protocols. The journal is characterized by the rapid reporting of reviews, original research and clinical studies across all disease areas.

\section{Dovepress}

A key focus is the elucidation of disease processes and management protocols resulting in improved outcomes for the patient.The manuscript management system is completely online and includes a very quick and fair peer-review system. Visit http://www.dovepress.com/ testimonials.php to read real quotes from published authors. 